\title{
The Gondwanan connection - Southern temperate Amanita lineages and the description of the first sequestrate species from the Americas
}

Truong, Camille ${ }^{1}$; Sánchez-Ramírez, Santiago ${ }^{2}$; Kuhar, Francisco ${ }^{3}$; Kaplan, Zacharie ${ }^{1}$; Smith, Matthew E. ${ }^{1}$

${ }^{1}$ University of Florida, Department of Plant Pathology, 2523 Fifield Hall, Gainesville FL 32611, USA

${ }^{2}$ Department of Ecology and Evolutionary Biology, University of Toronto, 100 Queen's park, Toronto, Ontario, M5S 2C6, Canada

${ }^{3}$ Centro de Investigación y Extensión Forestal Andino Patagónico (CONICET), Ruta 259, Km 4, Esquel 9200, Chubut, Argentina *Corresponding author: camille.truong@ufl.edu, phone +1 (352) 2734670

\begin{abstract}
Amanita is a diverse and cosmopolitan genus of ectomycorrhizal fungi. Although most species fruit aboveground, some sequestrate taxa have been documented from Australia and the Mediterranean region. We describe A. nouhrae sp. nov., a new hypogeous ('truffle-like') species associated with Nothofagus antarctica in northern Patagonia. This constitutes the first report of a sequestrate Amanita from the Americas. Thick-walled basidiospores ornamented on the interior spore wall ('crassospores') were observed consistently in A. nouhrae and its sister epigeous taxon A. morenoi. A. morenoi is a rarely collected but apparently common species from northern Patagonia that has sometimes
\end{abstract}


been misidentified as the Australian taxon A. umbrinella. Nuclear $18 \mathrm{~S}$ and 28S ribosomal DNA and mitochondrial 16S and 26S DNA placed these two species in a southern temperate clade within subgenus Amanita, together with other South American and Australian species. Based on a dated genus-level phylogeny, we estimate that the southern temperate clade may have originated near the Eocene/Oligocene boundary (ca. $35 \mathrm{Ma} \pm 10 \mathrm{Ma}$ ). This date suggests a broadly distributed ancestor in the Southern Hemisphere, which probably diversified as a result of continental drift, as well as the initiation of the Antarctic glaciation. By comparison, we show that this clade follows an exceptional biogeographic pattern, within a genus otherwise seemingly dominated by Northern Hemisphere dispersal.

Keywords: ectomycorrhizas, truffles, biogeography, Southern Hemisphere, Agaricales, Nothofagaceae

\section{Introduction}

Southern Hemisphere biogeography was heavily influenced by the fragmentation of the supercontinent Gondwana during the last 165 million years, causing the isolation and subsequent diversification of the ancestral Gondwanan biota on each separate continent (Raven and Axelrod 1972). The ectomycorrhizal (ECM) plant family Nothofagaceae (Fagales) is a prime example of this vicariant scenario, reflected in its current transoceanic distribution in South America, Australia, New Zealand, New Caledonia, and New Guinea (Manos 1997; Sanmartin and Ronquist 2004). Abundant fossil and pollen records place the origin of this plant lineage in the Cretaceous ca. $80 \mathrm{Ma}$ 
(million years ago) (Knapp et al. 2005). At the time, Antarctica had a warm-temperate climate and was probably covered by forest until ca. 25 Ma thereby favouring biotic exchanges between what is now South America and Australia. Australia and South America landmasses remained in contact via Antarctica until the final break-up of Gondwana ca. 50-35 Ma (Knapp et al. 2005; Sanmartin and Ronquist 2004). This so called 'Southern Gondwana' pattern was first illustrated by Brundin (1966) who demonstrated that phylogeographic patterns of chironomid midges (Diptera) were congruent with the sequential breakup of continents from the Gondwana landmass: African taxa are the earliest diverging lineages followed by a New Zealand-New Caledonia clade and finally a southern South America-Australian-New Guinea clade (Sanmartin and Ronquist 2004).

Despite the wealth of biogeographical data in many plant and animal groups (Sanmartin and Ronquist 2004), there have been fewer studies illustrating similar patterns in fungi. Enhanced diversity in certain ECM fungal lineages (e.g. /cortinarius) was detected simultaneously in forest soils from South America and Australia (Dickie et al. 2009; Nouhra et al. 2013; Tedersoo et al. 2008), suggesting that this ancient 'Southern Gondwana' connection may also occur in fungi (Tedersoo et al. 2014; Tedersoo et al. 2010). Global patterns of ECM fungal diversity also suggest that Austral regions (Australia, New Zealand, and southern South America) share specific fungal lineages, while lacking other lineages commonly found in the Northern Hemisphere (Tedersoo et al. 2010; Truong et al. 2017). These distribution patterns are often consistent with the evolutionary history of their host plants. Due to their long history of isolation, plant lineages native to the Southern Hemisphere (e.g. Nothofagaceae) formed specific ECM 
associations that are absent in Holarctic (Pinaceae, Betulaceae, Fagaceae) and tropical (Caesalpiniaceae, Dipterocarpaceae) ECM plant families (Tedersoo et al. 2012). Examples of these 'Austral' fungal lineages include the /austropaxillus lineage (Austropaxillus and Gymnopaxillus) (Skrede et al. 2011), the family Gallaceaceae (Hallingea and relatives) (Hosaka et al. 2008), and the /descolea lineage (Tedersoo et al. 2010). All of these taxa are known to form ECM associations with trees in the Nothofagaceae. The ascomycete genus Cyttaria (Peterson et al. 2010) is another example of this 'host-associated' biogeographic pattern, this time as an obligate plant pathogens of Nothofagaceae. Another scenario is the presence of southern temperate lineages within otherwise cosmopolitan ECM fungal genera, as previously demonstrated in Amanita sect. Caesareae (Sánchez-Ramírez et al. 2015b), Inocybe (Matheny et al. 2009), Hysterangium (Hosaka et al. 2008) and Laccaria (Wilson et al. 2017).

Sequestrate basidiomycetes (such as false truffles and puffballs) have highly modified fruiting morphologies where basidia mature inside enclosed, belowground (fully hypogeous) or partially emergent (secotioid) basidiomes adapted to passive (nonballistosporic) spore dispersal (Bougher and Lebel 2001). Several advantages have been suggested to favour the evolution of sequestrate basidiomes, such as protection against drought or cold (Thiers 1984), or enhanced dispersal abilities due to animal mycophagy (Fogel and Trappe 1978; Hosaka et al. 2008; Johnson 1996; Schickmann et al. 2012). With two Mediterranean climatic regions and the presence of numerous mammals as potential dispersal vectors, Australia is a 'hot spot' for sequestrate fungi (Bougher and Lebel 2001) including within several families of Agaricomycetes (e.g. Russulaceae, Cortinariaceae, and Amanitaceae). Amanita Pers. (Amanitaceae, Agaricales) is a diverse 
and cosmopolitan genus comprising about 500 accepted species and about 1,000 estimated species (Tulloss 2005). The species diversity is relatively low in South America compared to other regions and diversity patterns indicate a disjunction between southern South America and the rest of the continent (Tulloss 2005). The vast majority of species produce typical agaricoid (aboveground) basidiomes, but a few sequestrate taxa have been recorded from Australia and the Mediterranean region. The genera Torrendia and Amarrendia were initially erected to accommodate these sequestrate taxa. Torrendia included taxa with secotioid basidiomes whereas species of Amarrendia included the fully sequestrate, hypogeous species. Moncalvo et al. (2002) demonstrated that these taxa were phylogenetically nested within Amanita and later Justo et al. (2010) transferred all these sequestrate species to Amanita.

Here we describe a new sequestrate Amanita species discovered during our mycological explorations in Nothofagus forests of Patagonia. We also provide new morphological and molecular data for the sister taxon of $A$. nouhrae, the epigeous species A. morenoi Raithelhuber, that was previously known only from the type specimen. We document this mushroom and its unusual globose, ornamented basidiospores and discuss the origin and evolutionary significance of ornamented basidiospores in A. nouhrae and A. morenoi. Based on multi-gene phylogenies, we elucidate their phylogenetic relationships and track their temporal origins with respect to other Amanita species from Australia and southern South America.

\section{Materials and Methods}


Basidiomes of agaricoid and sequestrate Amanita species were collected in Nothofagus forest sites in Patagonia (Argentina and Chile) during spring 2015 and 2016 (Southern Hemisphere autumn). Specimens were photographed in the field and fresh tissues were preserved in CTAB buffer for subsequent DNA extraction. Colour codes in descriptions followed the Pantone colour code adopting the CMYK system referring to a Pantone colour bridge (Pantone Inc., New Jersey). Specimens were preserved on a forced-air dryer and stored in plastic bags with silica gel. A stereomicroscope was used to complete measurements of tissues (e.g. peridium, stipe, gleba). Dried material was rehydrated and mounted in water, $3 \% \mathrm{KOH}$, Melzer's reagent, and cotton blue to be studied by light microscopy. Spores, basidia, and other microscopic features were measured with $\geq 20$ measurements that were averaged to estimate size ranges. Specimens were deposited at the Museo Botánico of Córdoba (CORD), the Museo Nacional de Historia Natural of Santiago (SGO), and the Florida Museum of Natural History (FLAS). We extracted DNA from representative Amanita species collected from South America and Australia using a standard CTAB procedure (Gardes and Bruns 1993). The nuclear 18S and 28S ribosomal DNA and mitochondrial 16S and 26S DNA loci were amplified by PCR following Wolfe et al. (2012b). PCR products were verified by electrophoresis on $1.5 \%$ agarose gel, cleaned with EXO and SAP enzymes (Glenn and Schable 2005), and sequenced with the same primer combinations using the BigDye Terminator v. 3.1 Cycle Sequencing Kit on an ABI3700 DNA sequencer (Applied Biosystems) at University of Florida. Sequences were edited with Sequencher 5.1 and a BLAST search was performed in GenBank to verify their identity. We generated a total of 45 new sequences from 15 specimens and combined them with published datasets, 
including all known sequestrate Amanita species and as many species as possible from the Southern Hemisphere (Cai et al. 2014; Justo et al. 2010; Sánchez-Ramírez et al. 2015b; Wolfe et al. 2012b). Species of Pluteus and Limacella were used as outgroup taxa. Species, specimens and Genbank accession numbers are detailed in Supplementary Table S1.

Sequences from each gene were aligned with MUSCLE 3.8.31 (Edgar 2004) using default parameters, then corrected manually and ambiguously aligned regions excluded in Mesquite 3.01. The absence of incongruence among genes was verified before concatenating the data by reconstructing individual gene trees using Maximum Likelihood (ML) with 1000 bootstrap pseudoreplicates and the GTR+G model in RAxML 8.2.8 (Stamatakis 2014) on the CIPRES Portal (Miller et al. 2010). Three partitions (18S, 28S, 16S+26S) were selected with PartitionFinder 1.1.1 (Lanfear et al. 2012) with the BIC criterion. The concatenated dataset was analyzed similarly using ML and Bayesian inference (BI) in MrBayes 3.2.6 (Ronquist et al. 2012) with the GTR+G+I model for 10 million generations, 3 runs, and 4 chains. Convergence of the BI runs was verified in Tracer 1.5 (Rambaut and Drummond 2007) and the majority rule consensus tree was reconstructed by pooling sampled trees after discarding the first $25 \%$ as burn-in.

Our molecular dating analysis included an additional set of 327 nuclear large subunit rDNA (28S) sequences deposited in Genbank (Table S2), focusing on species level sampling and records that included geographic location (Sánchez-Ramírez et al. 2017). We used BEAST v2.4.5 (Bouckaert et al. 2014) on a supercomputer mainframe (SciNet, UofT) by choosing a lognormal-distributed clock model, the pure-birth Yule model as a tree prior, and a GTR+G substitution model. A gamma distribution was used 
as prior for the ucldMean (beta $=0.001$, alpha $=1$ ) and birthRate (beta $=0.01$, alpha $=1$ )

parameters. As calibration points we used two secondary calibrations based on SánchezRamírez et al. (2015b; 2017), calculated from primary fossil data: 1) on the time to the most recent common ancestor (tMRCA) of subgenus Amanita (normal distribution with mean=75.0 Ma and $\mathrm{SD}=1.0 \mathrm{Ma}$ ); and 2) on the tMRCA of Amanita section Caesareae (normal distribution with mean=56.0 Ma and $\mathrm{SD}=1.0 \mathrm{Ma}$ ). We ran two parallel MCMC runs of 100 million generations sampling every 10,000th state. Runs were evaluated for convergence and chain mixing in Tracer v1.6 (Rambaut and Drummond 2007). Then, runs were combined with LogCombiner, removing a 10\% burnin, and resampling every 20,000th state. The final tree file included 9000 states, which were processed with TreeAnnotator, estimating node heights using the 'ca' (common ancestor) method (Heled and Bouckaert 2013), and summarized posterior node data to a maximum-cladecredibility (MCC) tree. Only nodes with posterior probabilities $\geq 0.9$ were annotated.

\section{Results}

\subsection{Phylogenetic analysis}

The final alignment from the four concatenated genes included $2753 \mathrm{bp}$ and 1318 variable characters. The alignment is available in TreeBase (http://purl.org/phylo/treebase/phylows/study/TB2:S20736). The BI majority rule consensus tree $(\mathrm{LnL}=-29052.09)$ inferred from the multi-gene dataset is illustrated in Fig. 1. It contains 84 highly supported internodes (posterior probabilities $P P \geq 0.95$ ). The bestscoring ML tree (LnL-30259.44) was almost identical to the Bayesian tree, with 71 highly supported internodes (bootstrap values $\mathrm{BS} \geq 0.70$ ). The single-gene tree from the 
nuclear large subunit rDNA (28S) was the most complete dataset and had 54 highly supported internodes. Nevertheless, no incongruence was observed among genes and the concatenation of $28 \mathrm{~S}$ with $18 \mathrm{~S}, 26 \mathrm{~S}$ and $16 \mathrm{~S}$ provided additional resolution at important nodes.

As previously reported (Justo et al. 2010; Tulloss et al. 2016; Wolfe et al. 2012b), the genus Amanita is subdivided into two highly supported clades corresponding to subgenera Amanita and Lepidella, while non-ectomycorrhizal species form paraphyletic sister lineages. These species were discovered in the absence of known ECM host plants and are currently considered to be either putative saprobes or root endophytes (Moncalvo et al. 2002; Wolfe et al. 2012a). Redhead et al. (2016) segregated these non-ECM species into the new genus Saproamanita. Although the monophyly of ECM Amanita species is unequivocal, the generic concept of Saproamanita have been contested based on the lack of morphological characters and the fact that this genus may be a paraphyletic grade of species rather than a true monophyletic group (Tulloss et al. 2016). The generic delimitation of Amanita is beyond the scope of this paper and we therefore retained all species within the genus Amanita until further work clarifies the nomenclature of this group.

All the South American species included in this study belong to subgenus Amanita. With the exception of the South American taxon A. diemii, all taxa studied formed a highly supported southern temperate clade together with Australian species (Fig. 1). Members of this clade correspond roughly to the 'Amarrendia clade' described in Justo et al. (2010). This lineage includes both sequestrate (e.g. A grandis, A grandispora, A. inculta, A. pseudoinculta and A. oleosa from Australia, as well as our newly described 
species A. nouhrae from South America) and epigeous taxa (e.g. A. umbrinella and A. murinoflammeum from Australia, as well as A. morenoi and A. merxmuelleri from South America). Amanita nouhrae and its sister taxon A. morenoi share the presence of ornamented basidiospores (see below) that are absent in their closest known relative $A$. merxmuelleri and other described species from the Southern temperate clade.

\subsection{Divergence time estimation}

The time-calibrated molecular phylogeny based on our dataset with the addition of $32728 \mathrm{~S}$ sequences from Genbank gave an estimated age of the root of the genus Amanita (including non-ECM taxa) with a mean of 99.9 Ma [98.0-101.9 HPD] (Fig. 2), fairly close to posterior estimates in other studies (Cai et al. 2014; Ryberg and Matheny 2012). The tMRCA of the southern temperate clade -which includes our newly described species A. nouhrae- had a mean of 34.5 Ma [24.3-45.45 HPD], falling near the Eocene/Oligocene boundary (Fig. 2). Within this clade, the South American cluster resulted with a mean tMRCA of $24.4 \mathrm{Ma}$ [13.1-33.2 HPD]. It is worth mentioning that in previous analyses (data not shown), a different calibration prior based on Cai et al. 2014 at the root of the genus Amanita (158.5 Ma [116.6-200.7 HPD]) resulted in slightly older ages (ca. $10 \mathrm{Ma}$ ), which suggests that our estimates are probably conservative at the upper range of the distribution.

\subsection{Taxonomy}

Amanita morenoi Raithelhuber, 1986. Metrodiana 14: 6 (1986).

(Fig. 3) 
Type: Argentina, Neuquén, Nahuel Huapi National Park, Lago Espejo, 9 March 1959, coll. I. Gamundi ‘Amanita 75’. BAFC!-Holotype 30.617 (Supplementary Fig. S3) Macromorphology. Pileus 20-60 mm diam., convex when young, applanate when fully developed, with various shades of beige (P406) to pale grey (P413), cream (P466-468) or brownish (P463-464); margin distinctly crenulate from striations; patches of universal veil irregularly distributed over the disc, almost absent to very abundant, flattened to thickened toward the centre of disc, whitish to beige (P406-407) or greyish (P420-421). Lamellae free to narrowly adnate, 6-8 per cm, white to cream, with approximately one lamellula in between each lamella, margin finely notched when viewed through a hand lens. Stipe $70-120 \times 8-10 \mathrm{~mm}$, slightly thicker towards base, cream to beige (P4645, P4655), whitish at apex, distinctly fibrillose, remnants of veil material sparse to very abundant and scaly along stipe, whitish to beige (P406-407) or greyish (P420-421); annulus concolorous with veil remnants (P406-407, P420-421), descending, distinctly striated. Base bulbous, $25 \times 18 \mathrm{~mm}$, encircled with cream (P466467) to beige (P406-407) circumsessile volva. Context trama whitish and smooth, no response with the addition of Melzer's reagent on any basidiome surfaces; pileus trama slightly darker (P4625, P4635, P4645) on uppermost part where it contacts the pileipellis, 3-6 mm thick above stipe, regularly narrowing towards margins; stipe trama whitish, regularly hollow from base to cap in mature specimens. Odor and taste indistinct.

Microscopic characteristics. Basidiospores globose to subglobose, with an apiculum, hyaline, non-amyloid, (9) 10-12.5 (13) × (8) 9-11.5 (13) $\mu \mathrm{m}, \mathrm{Q}$ ratio $=1-1.15$, thick-walled $(0.8-1 \mu \mathrm{m})$, distinctly ornamented on the inner wall (crassospores as described and depicted by (Tulloss and Halling 1997)); ornamentation consisting of small, 
evenly distributed hemispherical pits that are covered by an outer layer (ectosporium) appressed to the inner layer, the outer layer eventually collapsing into the cavities; in immature specimens spores are scarce, mostly with thin and smooth cell walls $(<0.8 \mu \mathrm{m})$, a few ornamented spores visible after careful examination even in young specimens. Basidia clavate-pedicellate, $30-50 \times 10-15 \mu \mathrm{m}$ from base to bottom of sterigmata, typically 4 -spored but occasionally 2 -spored, thin walled $(<0.5 \mu \mathrm{m})$, ornamented basidial walls (crassobasidia) not observed; sterigmata short-cylindrical, 3-6 $\mu \mathrm{m}$ long. Subhymenium trama 30-50 $\mu \mathrm{m}$ thick, hyaline, consisting of elongated hyphae, tightly interwoven, horizontally distributed; immature specimens with oil droplets abundantly distributed in the hymenial and subhymenial trama and inside basidia; clamp connections infrequent but visible in all trama (hymenium, pileus, stipe).

Habitat and distribution. On soil in Nothofagus dombeyi forest in northern Patagonia.

Additional specimens examined. Argentina, Río Negro, Nahuel Huapi National Park, near Lago Escondido, 16 May 2016, coll. M. E. Smith MES1301 (FLAS-F-59751). Chile, Los Ríos, Puyehue National Park, up the road past El Caulle, North of Rio Golgol: 4 May 2016, coll. R. Healy MES1616 (FLAS-F-59753), coll. A. E. Mujic MES1624 (FLAS-F-59754), coll. P. Sandoval MES1588 (FLAS-F-59755); 7 May 2016, coll. B. P. Matheny MES1774 (FLAS-F-59752).

Additional notes. In their description of the type specimen, Tulloss and Halling (1997) depicted basidiospores with regular 'golf ball' ornamentation on the inner wall that match perfectly with our own observations of the type specimen (Fig. S3) and our own fresh collections (Fig. 3). These ornamented basidiospores were first reported from 
European Amanita species by Kotilová-Kubičková and Pouzar (1988) and were referred to as 'crassospores'. These crassospores occurred together with 'normal' spores (thin and non-ornamented walls) and were observed inconsistently in several Amanita species. Kotilová-Kubíčková and Pouzar (1988), and later Tulloss and Halling (1997) therefore postulated that they were anomalous spores resulting from a pathogenic infection or other environmental factors. In our collections of A. morenoi and A. nouhrae, mature spores were consistently and distinctly ornamented in all studied specimens. Immature specimens with young basidia had few spores in general but crassospores were nonetheless present upon close examination. Amanita morenoi and A. nouhrae clustered in highly supported sister lineages within our phylogeny (Fig. 1), suggesting that these ornamented spores may be genetically determined and are not due to environmental influences or pathogens. We obtained specimens of A. morenoi from several sites on different days, further bolstering the hypothesis that these spores are a normal feature for this species. Although our collections match well with the description of A. morenoi, we did not observe the 'crassobasidia' described by Tulloss and Halling (1997) in which basidia walls are ornamented in a similar way. We cannot explain this morphological deviation from their observations of the type but morphological studies of additional collections of A. morenoi may reveal more about these 'crassobasidia.' Tulloss and Halling (1997) also observed crassopsores in A. pseudospreta from Patagonia, but this species supposedly has a sacate volva and the presence of crassospores was inconsistent within their material. The overall similarities between A. morenoi and A. pseudospreta and the fact that these two taxa were described from the same region in northern 
Patagonia suggest that they could be sister species or perhaps even synonyms. However, careful study of additional material is needed to investigate this hypothesis.

Amanita morenoi was previously known only from the type specimen. In their description of the dry specimen, Tulloss and Halling (1997) depicted a species with a pale brown cap and pyramidal to subconical warts over the disc. They did not have access to fresh material for their descriptions. According to the annotation notes in the holotype packet by Tulloss and Halling: 'the specimen appears to be somewhat damaged when dried and is not in very good condition. Large thick brown warts that may have been truncate or pyramidal decorate the disc.' We did not observe pyramidal warts over the disc on our fresh material but the thick brown warts fit well with their description. As depicted in Fig. 3, A. morenoi specimens with almost identical 18S and 28S rDNA as well as $16 \mathrm{~S}$ and $26 \mathrm{~S}$ mitochondrial DNA sequences can be quite variable morphologically, especially in the colour and abundance of veil material left on the pileus and stipe. The overall description of morphology (i.e. striate pileus margin, bulbeous base) and crassospores matches well with the type and with the description of Tulloss and Halling (1997). In addition, our collections are from the same area and at the same time of year as the type specimen, in a region were the diversity of Amanita species is relatively low. Amanita morenoi apparently fruits abundantly during the Austral fall and specimens have been previously misidentified as the Australian taxon A. umbrinella (Singer 1954, see also Tulloss in www. amanitaceae.org). In our phylogeny (Fig. 1), A. umbrinella sensu stricto (Gilbert 1941) is phylogenetically segregated and clearly distinguished by the thin-walled, smooth basidiospores. Based on these observations, we use the name A. morenoi to refer to this taxon. 
Type: Argentina, Río Negro, Nahuel Huapi National Park, Los Rapidos, 13 May 2016, coll. M. E. Smith MES1921. Holotype-CORD, isotype-FLAS (FLAS-F-59756).

Diagnosis. Basidiome hypogeous, subglobose, with a sterile base almost entirely encircled by the gleba at maturity. Peridium, stipe, and gleba white to cream. Gleba loculate. Basidiospores 12.5-17.5 ×14-20 $\mu \mathrm{m}$, subglobose, hyaline, inamyloid, with an obvious oil droplet, thick spore walls $(1-2 \mu \mathrm{m})$ and ornamentation on the inner wall. First sequestrate Amanita species recorded from South America. Known only from Nahuel Huapi National Park (northern Patagonia) in association with Nothofagus antarctica. Macromorphology. Basidiome hypogeous, subglobose, 10-16 $\mathrm{mm}$ across at maturity, almost entirely enclosed by the universal veil. Peridium white to cream (P465), becoming yellowish (P100) when dry, thickest in the apical part (up to $0.5 \mathrm{~mm}$ thick), densely floccose with cream to brownish (P4635, P4645, P4655) universal veil remnants forming patches on upper surface. Gleba hyaline when young, turning white to slightly yellowish (P100) or cream (P468) with age; hymenium loculate, individual locules irregular or angular to circular, up to $0.7 \mathrm{~mm}$ across. Sterile base white to cream (P465), with a smooth exterior surface, subglobose when young (up to $1.2 \mathrm{~cm}$ diam.), becoming conic and almost entirely encircled by gleba as the basidiome develops. Context trama whitish and smooth, no response with the addition of Melzer's reagent on any basidiome surfaces. Odor and taste indistinct. 
Microscopic characteristics. Basidiospores highly variable in size and shape within a basidiome, subglobose to deformed, with an apiculum, hyaline, inamyloid, bearing an oil droplet, 14-20 (22) $\times(12) 12.5-17.5$ (19) $\mu \mathrm{m}, \mathrm{Q}$ ratio $=1.05-1.25$; mature spores thick-walled (1-2 $\mu \mathrm{m}$ thick) and distinctly ornamented on the inner wall (crassospores), ornamentation consisting of small irregular cavities ( $0.5 \mu \mathrm{m}$ diam.) offering a false verrucose appearance that is often obscured by the oil droplet, forming a meshed reticulum of small irregular pits (Moreno et al. (2012) illustrate similar spore ornamentation in their description of Choiromyces magnusii (Mattir.) Paol.), inner wall covered by an adpressed outer layer (ectosporium) that eventually collapse into the cavities; in immature specimens, spores rare, with a thin and smooth wall $(<1 \mu \mathrm{m})$. Basidia clavate-pedicellate, $30-40 \times 10-12 \mu \mathrm{m}$ from base to bottom of sterigmata, $1-3$ spored (4-spored basidia not observed), soon collapsing after spore release and therefore challenging to observe in mature basidiomes, ornamented basidia walls (crassobasidia) not observed; sterigmata cylindrical, 7.5-12 $\mu \mathrm{m}$ long. Subhymenial trama consisting of elongated, tightly interwoven hyphae, horizontally distributed, hyaline (lighter than the hymenium), 30-40 $\mu \mathrm{m}$ thick; immature specimens with oil droplets abundantly distributed in the hymenial and subhymenial trama, and inside basidia; peridium composed of large, irregularly polyhedral cells, $20-50 \mu \mathrm{m}$ long, with thin, yellowish to green-brown walls; clamp connections infrequent but visible in all trama (hymenium, pileus, stipe).

Etymology. This species is named after Dr. Eduardo Nouhra to honour his important and lasting contributions to the study of hypogeous fungi of Patagonia. 
Habitat and distribution. In deep soil under Nothofagus antarctica in northern Patagonia; associated with areas of animal digging.

Additional specimens examined. Argentina, Río Negro, Nahuel Huapi National Park, Los Rapidos: 8 May 2015, coll. R. Healy MES1126 (FLAS-F-59758); 11 May 2015, coll. L. Fernandez MES1213 (FLAS-F-59759).

Additional notes. At first glance the basidiomes of A. nouhrae are similar to an immature button of an epigeous Amanita. However, upon closer inspection, the loculate gleba makes it clear that it is a mature, sequestrate basidiome. Thus far this species is known only from a single location in Nahuel Huapi National Park in northern Patagonia. It is possible that this is a rare or narrowly endemic species but it may also be easily overlooked as a button of an epigeous Amanita species.

Amanita nouhrae is distinct from any other Amanita species due to a combination of the hypogeous, sequestrate habit and the large, thick-walled and ornamented basidiospores. The epigeous sister taxon A. morenoi (Fig. 1) has similar basidiospore ornamentation but with a more regularly and evenly distributed pattern on the spore surface. Amanita nouhrae differs from the two other known hypogeous species (A. grandispora and A. oleosa) by its distinct ornamented spores. In addition, spores in both A. grandispora and A. oleosa are smaller $(13-17 \times 9.5-11.5 \mu \mathrm{m}$ and $12.5-15 \times 9-11 \mu \mathrm{m}$, respectively) and narrower ( $\mathrm{Q}$ ratio > 1.30) (Bougher and Lebel 2002). Both species occur in Australia in association with Eucalyptus and A. oleosa is notably different in having locules in the gleba that are filled with a clear liquid.

\section{Discussion}




\subsection{Southern temperate clade within subgenus Amanita}

Based on our multi-gene phylogeny, the new species $A$. nouhrae clusters with other epigeous and sequestrate species from Australia and southern South America in a highly supported Southern temperate clade (Fig. 1). With the addition of A. nouhrae this clade includes five species of sequestrate Australian taxa; the secotioid species A. grandis, A. inculta, and A. pseudoinculta (with stipitate and partially emergent basidiomes), as well as the hypogeous, fully sequestrate species $A$. grandispora and A. oleosa (with astipitate and belowground basidiomes). Four additional epigeous species belong to this clade; A. merxmuelleri and A. morenoi are from South America whereas A. umbrinella and A. murinoflammeum are from Australia.

Our time-of-divergence analysis suggests that the tMRCA of the southern temperate is found most likely within the Eocene (Mean=34.5 Ma, Fig. 2). This timeline potentially fits with paleogeographic reconstructions of the final break-up of Gondwana suggesting that complete isolation between Australia and South America occurred around $35 \mathrm{Ma}$ (Knapp et al. 2005; Sanmartin and Ronquist 2004). The initiation of the Antarctic glaciation around that time (DeConto and Pollard 2003) reinforced the termination of biotic exchanges between the two regions. In addition, divergence within the southern temperate clade probably occurred as a result of continental drift and the gradual isolation of both Australia and southern South America from the Antarctic Peninsula in the Eocene (50-35 Ma) and the Oligocene (ca. $30 \mathrm{Ma}$ ) respectively, as also documented for other organisms (Sanmartin and Ronquist 2004).

Hosaka et al. (2008) found similar results in one Hysterangium lineage (clade II), in which a potential vicariant event was associated with the separation of Australia and 
southern South America from a common ancestor distributed across these landmasses. In an alternative scenario, Skrede et al. (2011) found two distinct clades of Austropaxillus, one from South America and another from Australasia. They estimated the divergence time of these two clades at ca. $22 \mathrm{Ma}$, suggesting that dispersal rather than vicariance may have occurred. Wilson et al. (2017) attributed the current worldwide distribution of Laccaria to dispersal events from an Australasia ancestor that originated ca. $64 \mathrm{Ma}$. They estimated the divergence time of two southern South American Laccaria species with their Australian sister lineage at 20.49 Ma, but additional sampling from this region may reveal the presence of Southern Gondwanan vicariance from their Australian ancestor. Indeed, long-distance intercontinental dispersal over geological time-scales has been reported rather episodically (Moncalvo and Buchanan 2008; Moyersoen et al. 2003) and the combination of ancient vicariant patterns with more recent dispersal events is a potential scenario in many groups (Sanmartin and Ronquist 2004), including in fungi. For example, a mosaic of vicariant and dispersal events apparently contributed to the historical biogeography of the family Inocybaceae (Matheny et al. 2009). In the case of the Nothofagaceae-parasitic genus Cyttaria, isolation by vicariance was detected across South American and Australian species in addition to a more recent long distance dispersal event from Australia to New Zealand (Peterson et al. 2010). This pattern matches almost perfectly with the phylogeographic history of the host trees (Knapp et al. 2005). Our incomplete sampling does not comprise many Amanita species from New Zealand and only a handful of taxa from Australia. Therefore, we cannot exclude the existence of recent long-distance dispersal events within subgenus Amanita or the 
Southern temperate clade. Based on our results, however, the ancestor of this southern temperate clade is very likely to be of Southern Gondwanan origin.

Previous biogeographic studies based on dated molecular phylogenies in Amanita (and other ECM groups) have shown a pattern where ancient lineages of Paleotropical origins (e.g. Africa or Asia) subsequently disperse through land-bridges, most of them in the Northern Hemisphere (Matheny et al. 2009; Sánchez-Ramírez et al. 2015b). This contrasts with our findings that members of the southern temperate clade are all from Austral regions and share a common ancestor of relatively ancient origin within the genus Amanita, potentially due to their long history of isolation. At first glance in our genuslevel dated phylogeny (Fig. 2), the lack of sampling and/or diversity in southern South America is noticeable, particularly in comparison with the Australian taxa, which seem to be more commonly associated with Eurasian, African, and even North American lineages. Although more sampling of southern South American species is needed, their estimated diversity seems to be particularly low compared to other regions (Truong et al. 2017). Higher diversity in Australia compared to southern South America could be a result of higher dispersal from the Paleotropics during the Miocene (Sánchez-Ramírez et al. 2015b; Sanmartin and Ronquist 2004). In contrast, South America remained isolated until the Pliocene (ca. 2.5 Ma) when the Panamá Isthmus closed. Moreover, Wilson et al. (2017) estimated that the rate of diversification of Northern Hemisphere Laccaria lineages was more than twice that of the Southern Hemisphere. They correlated it to the higher availability of new niches by mean of switching to different ECM host-plant families. Similarly, higher diversification rates in Amanita sect. Caesareae from temperate regions compared to the tropics was associated with higher number of 
ecological niches for ECM fungi, i.e. more complex soil horizons and more diverse ECM hosts (Sánchez-Ramírez et al. 2015a). Niche partitioning such as specificity of host-plant, soil horizons, and/or microclimate, may indeed promote sympatric speciation, as

demonstrated in the A. muscaria species complex (Geml et al. 2014). In southern South America, the low diversity of Amanita species could potentially be explained by limited host availability, as well as reduced dispersal due to isolation and geographic barriers (Tulloss, 2005; Sánchez-Ramírez et al. 2015b).

One notable difference between South American and Australian taxa from the Southern temperate clade is that Australian species have been documented in habitats with Eucalyptus or Acacia as the primary host trees (Justo et al. 2010, www.amanitaceae.org), whereas southern South American species are associated with Nothofagaceae. Sequestrate species are easily overlooked, therefore we suspect that there may be additional Australasian species associated with Nothofagaceae that remain unknown or undescribed. In addition, the recent discovery of an Eucalyptus fossil in Argentina from the early Eocene (ca. 51.9 Ma) (Gandolfo et al. 2011) falls before our tMRCA estimates of the southern temperate Amanita clade. Because of this, we cannot rule out the possibility of a Eucalyptus-associated ECM fungal ancestor in southern South America followed by a host switch to Nothofagus. Clearly more sampling of Southern Hemisphere Amanita species, particularly sequestrate taxa, is needed to resolve broader evolutionary patterns in this group.

\subsection{Evolution of the sequestrate habit within Amanita}


Compelling evidence from molecular studies suggests that sequestrate taxa evolved repeatedly from non-sequestrate ancestors within the Agaricomycetes (Hibbett 2007), e.g. in the Boletales (Binder and Hibbett 2006), the Russulales (Eberhardt and Verbeken 2004), or the Agaricales (Peintner et al. 2001). Once this trait is stable in a lineage, subsequent species radiations seem to occur only into sequestrate species, with no 'reversed evolution' into non-sequestrate species (Peintner et al. 2001). As previously reported in Justo et al. (2010), our results corroborate the findings that sequestrate species form polyphyletic lineages within the genus Amanita (Fig. 1). Ancestral state reconstruction of the sequestrate habit within our phylogenetic tree (data not shown) indicates that this trait has evolved repeatedly and relatively recently from nonsequestrate ancestors within the genus Amanita. For a genus that otherwise includes mostly epigeous species, the southern temperate clade comprises the highest number of sequestrate species to date, with five Australian taxa in addition to our newly described species A. nouhrae. Only three additional sequestrate Amanita are known from other lineages. The diversity of sequestrate Amanita species is still underexplored and our dataset probably underrepresents their true diversity. Nevertheless, based on our current knowledge, the southern temperate clade seems particularly prone to the evolution of the sequestrate habit.

All sequestrate Amanita species share similar macro- and micro-morphological features. They can only be distinguished based on a combination of characters, including stipe development (fully hypogeous or not), spore size and shape, the presence of clamp connections, and oil droplets visible in spores and reproductive tissues (Justo et al. 2010). Along with A. nouhrae, sequestrate species from the Southern temperate clade all share 
abundant clamp connections and oil droplets that are apparently rare or absent in other sequestrate Amanita lineages (e.g. A. arenaria, A. torrendii and 'Amarrendia sp.' H0909, a phylogenetically unique sequestrate species from Australia that remains undescribed) (Justo et al. 2010). Mature spores in A. nouhrae are unusual within Amanita because they are ornamented and thick-walled. Interestingly, in South America, both A. nouhrae (hypogeous) and A. morenoi (epigeous) have similar ornamented basidiospores, while their closest relative $A$. merxmuelleri has spores with thin and smooth walls. These ornamented 'crassospores' were reported inconstantly in other epigeous Amanita species and were believed to be an anomalous morph resulting from pathogenic infection (Kotilová-Kubíčková and Pouzar 1988; Tulloss and Halling 1997). We found that this character was consistent in all our collections of both $A$. morenoi and A. nouhrae, as well as in the type specimen of A. morenoi. These two species clustered as highly supported sister lineages within our phylogeny (Fig. 1), suggesting that this character is likely genetically determined. Ornamented spores occur rarely within Amanita but are a common feature in many hypogeous fungi regardless of their taxonomic affinity (Trappe et al. 2009). Ornamented, thick-walled spores are believed to be advantageous against the chemical and physical hazard of passing through animal digestive tracts (Fogel and Trappe 1978) or against the harsh climatic conditions in which these sequestrate taxa evolved (Thiers 1984). The examination of further material from various South American Amanita species is needed to fully understand the origin and evolution of this character. Nevertheless, the occurrence of a potential epigeous ancestor with ornamented spores may have favoured the evolution of the sequestrate habit in South America. It is notable that immature spores in A. nouhrae are similar to the spores described from sequestrate 
Australian species. It is difficult to make conclusive assumptions about spore ornamentation because of the paucity of material from most of these sequestrate species. However, it would be interesting to study additional Australian material in the future to see if some of these species may have ornamented spores in very mature specimens. Amanita nouhrae is found in a cool, moist continental climate in southern South America. In Australia, A. grandispora is known from temperate sites in Victoria and Tasmania that are similar to the site where A. nouhrae was collected. However, the remaining Australian sequestrate Amanita species are typically found in seasonally arid Mediterranean habitats and Justo et al. (2010) suggested that the evolution of sequestrate forms in Amanita correlated with aridification processes. Indeed (Sheedy et al. 2016) found an increased rate of sequestration in various Agaricomycetes groups from Australia during a period of aridification after the separation of Australia from Antarctica (ca. 30$15 \mathrm{Ma})$. Climatic models indicate a similar trend from a moist-warm climate to cooler temperatures and dryer seasons in southern South America after the separation with Antarctica during the Oligocene (ca. $30 \mathrm{Ma}$ ), favoring the establishment of steppe and arid vegetation that extended in the entire Patagonian region in the late Miocene (ca. 15 Ma) (Ortiz-Jaureguizar and Cladera 2006). Our data suggest that the divergence of the sequestrate species A. nouhrae from an epigeous ancestor is relatively recent (ca. 10-20 Ma, Fig. 2) and corresponds to this period. In addition, A. nouhrae is thus far known only from a forest of Nothofagus antarctica, a species that typically occurs in the transition with steppe vegetation on the Eastern side of the Andes. The paucity of data from the region does not allow us to make definite conclusions, but it would be interesting to investigate further whether past climatic oscillations toward a dryer climate may have 
favored the evolution of sequestrate species in other fungal groups that occur in southern South America, similarly to the pattern observed in Australia.

\section{Conclusions}

The diversity of ECM fungi in the Southern Hemisphere remains significantly understudied as compared to other regions and future work is likely to reveal many novel taxa (Tedersoo and Smith 2013; Truong et al. 2017). The 'southern Gondwana' connection between southern South America and Australia has been demonstrated in various groups (Sanmartin and Ronquist 2004), suggesting a history of biotic exchange that should also be reflected in fungi (Tedersoo et al. 2014; Tedersoo et al. 2010). Here we demonstrated that the new sequestrate species A. nouhrae from northern Patagonia is genetically related to sequestrate taxa from Australia. We also estimated the tMRCA of this lineage near the Eocene/Oligocene boundary (ca. $35 \mathrm{Ma} \pm 10 \mathrm{Ma}$ ), a finding that is congruent with a 'southern Gondwanan' origin. Tracing such a relatively ancient connection between southern South America and Australia has been done in a few other ECM fungi so far (e.g. Hosaka et al. 2008; Matheny et al. 2009) and we expect that this pattern is much more common in Nothofagus-associated fungi than what has been previously documented.

\section{Acknowledgments}

This work was supported by the US National Science Foundation grant DEB 1354802 (to MES), an Advanced Postdoc Mobility Fellowship from the Swiss National Science Foundation (to CT), a Friends of the Farlow Fellowship from Harvard Universiy 
(to FK), and the UF Institute for Food and Agricultural Sciences IFAS (to MES). Dr. Eduardo Nouhra (University of Cordoba) helped to obtain permits and the Administración de Parques Nacionales of Argentina kindly authorized our collecting expeditions in Parque Nacional Nahuel Huapi and Parque Nacional Lanín under Projecto 2016/720 (to E. Nouhra). In Tierra del Fuego, Dr. Alicia Moretto provided guidance in obtaining research permits and the Secretaría de Desarollo Sustentable y Ambiente graciously authorized the collection of specimens under Resolución S.D.S. y A. NRO. 0218/2015 (to CT). The Chilean Corporación Nacional Forestal (Gerencia de Areas Silvestres Protegidas) provided permission to collect fungi in Puyehue National Park under permit No. 014/2014 (to MES). Eduardo Nouhra, Giuliana Furci, and Natalia Fernández offered critical guidance during fieldwork, while Lisandro Fernández, Rosanne Healy, Brandon P. Matheny, Alija E. Mujic, Hugo Pereyra and Pablo Sandoval provided additional collections of fresh specimens. Several members of the research team also graciously provided photographs. Dr. Alfredo Justo and Dr. David Hibbett (Clark University) kindly provided DNA extracts from Australian species of Amanita. We thank Susana Pereira and Andrea Romero (BAFC herbarium) for their assistance and curators from the herbaria of CORD, NYBG, and PERTH for generously sending specimens on loan. Laszlo Nagy and two anonymous reviewers provided valuable comments to improve the manuscript before publication.

\section{Literature}

Binder M, Hibbett DS, 2006. Molecular systematics and biological diversification of Boletales. Mycologia 98, 971-981. 
Bouckaert R, Heled J, Kuhnert D, Vaughan T, Wu CH, Xie D, Suchard MA, Rambaut A, Drummond AJ, 2014. BEAST 2: a software platform for Bayesian evolutionary analysis. PLoS Computational Biology 10, e1003537.

Bougher NL, Lebel A, 2001. Sequestrate (truffle-like) fungi in Australia and NewZealand. Australian Systematic Botany 14, 439-484.

Bougher NL, Lebel T, 2002. Australasian sequestrate (truffle-like) fungi. XII. Amarrendia gen. nov.: an astipitate, sequestrate relative of Torrendia and Amanita (Amanitaceae) from Australia. Australian Systematic Botany 15, 513-525 Brundin L, 1966. Transantarctic relationships and their significance, as evidenced by chironomid midges with a monograph of the subfamilies Podonominae and Aphroteniinae and the austral Heptagynae. K. Sven. Vetenskapsakad. Handl. 11. Cai Q, Tulloss RE, Tang LP, Tolgor B, Zhang P, Chen ZH, Yang ZL, 2014. Multi-locus phylogeny of lethal amanitas: implications for species diversity and historical biogeography. BMC Evolutionary Biology, doi: 10.1186/1471-2148-1114-1143. DeConto RM, Pollard D, 2003. Rapid Cenozoic glaciation of Antarctica induced by declining atmospheric CO2. Nature 421, 245-249.

Dickie IA, Richardson SJ, Wisera SK, 2009. Ectomycorrhizal fungal communities and soil chemistry in harvested and unharvested temperate Nothofagus rainforests. Canadian Journal of Forest Research 39, 1069-1079.

Eberhardt U, Verbeken A, 2004. Sequestrate Lactarius species from tropical Africa: $L$. angiocarpus sp. nov. and L. dolichocaulis comb. nov. Mycological Research 91, 10421052. 
Edgar RC, 2004. MUSCLE: multiple sequence alignment with high accuracy and high throughput. Nucleic Acids Research 32, 1792-1797.

Fogel R, Trappe JM, 1978. Fungus consumption (mycophagy) by small animals. Northwest Science 52, 1-31.

Gandolfo MA, Hermsen EJ, Zamaloa MC, Nixon KC, Gonzalez CC, Wilf P, Cuneo NR, Johnson KR, 2011. Oldest known Eucalyptus macrofossils are from South America. PLoS One 6, e21084.

Gardes M, Bruns TD, 1993. ITS primers with enhanced specificity for basidiomycetes - application to the identification of mycorrhizae and rusts. Molecular Ecology 2, 113-118.

Geml J, Pastor N, Fernandez L, Pacheco S, Semenova TA, Becerra AG, Wicaksono CY, Nouhra ER, 2014. Large-scale fungal diversity assessment in the Andean Yungas forests reveals strong community turnover among forest types along an altitudinal gradient. Molecular Ecology 23, 2452-2472.

Gilbert E-J, 1941. Amanitaceae. Iconographia Mycologica 27 (Suppl. 1), 203-427. Glenn T, Schable N, 2005. Isolating microsatelline DNA loci, in: Zimmer EA, Roalson EH (eds), Molecular Evolution: Producing the Biochemical Data, Part B. Academic Press, San Diego, CA, pp. 202-222.

Heled J, Bouckaert RR, 2013. Looking for trees in the forest: summary tree from posterior samples. BMC Evolutionary Biology 13, 221.

Hibbett DS, 2007. After the gold rush, or before the flood? Evolutionary morphology of mushroom-forming fungi (Agaricomycetes) in the early 21st century. Mycological Research 111, 1001-1018. 
Hosaka K, Castellano MA, Spatafora JW, 2008. Biogeography of Hysterangiales (Phallomycetidae, Basidiomycota). Mycological Research 112, 448-462.

Johnson CN, 1996. Interactions between mammals and ectomycorrhizal fungi. Trends in Ecology \& Evolution 11, 503-507.

Justo A, Morgenstern I, Hallen-Adams HE, Hibbett DS, 2010. Convergent evolution of sequestrate forms in Amanita under Mediterranean climate conditions. Mycologia 102, 675-688.

Knapp M, Stockler K, Havell D, Delsuc F, Sebastiani F, Lockhart PJ, 2005. Relaxed molecular clock provides evidence for long-distance dispersal of Nothofagus (southern beech). PLoS Biology 3.

Kotilová-Kubíčková L, Pouzar Z, 1988. Three types of basidiospores in Amanita. Česká Mykologie 42, 65-70.

Lanfear R, Calcott B, Ho SY, Guindon S, 2012. Partitionfinder: combined selection of partitioning schemes and substitution models for phylogenetic analyses. Molecular Biology and Evolution 29, 1695-1701.

Manos P, 1997. Systematics of Nothofagus (Nothofagaceae) based on rDNA spacer sequences (ITS): taxonomic congruence with morphology and plastid sequences. American Journal of Botany 84, 1137.

Matheny PB, Aime MC, Bougher NL, Buyck B, Desjardin DE, Horak E, Kropp BR, Lodge DJ, Soytong K, Trappe JM, Hibbett DS, 2009. Out of the Palaeotropics? Historical biogeography and diversification of the cosmopolitan ectomycorrhizal mushroom family Inocybaceae. Journal of Biogeography 36, 577-592. 
Miller MA, Pfeiffer W, Schwartz T, 2010. Creating the CIPRES Science Gateway for inference of large phylogenetic trees, Proceedings of the Gateway Computing Environments Workshop, New Orleans, LA, pp. 1-8. Moncalvo J-M, Buchanan PK, 2008. Molecular evidence for long distance dispersal across the Southern Hemisphere in the Ganoderma applanatum-australe species complex (Basidiomycota). Mycological Research 112, 425-436.

Moncalvo JM, Vilgalys R, Redhead SA, Johnson JE, James TY, Aime MC, Hofstetter V, Verduin SJW, Larsson E, Baroni TJ, Thorn RG, Jacobsson S, Clemencon H, Miller OK, 2002. One hundred and seventeen clades of euagarics. Molecular Phylogenetics and Evolution 23, 357-400.

Moreno G, Alvarado P, Manjón JL, 2012. Phylogenetic affiliation of Choiromyces magnusii and C. venosus (Tuberaceae Ascomycota) from Spain. Mycological Progress 11, 463-471.

Moyersoen B, Beever RE, Martin F, 2003. Genetic diversity of Pisolithus in New Zealand indicates multiple long-distance dispersal from Australia. New Phytologist $160,569-579$.

Nouhra E, Urcelay C, Longo S, Tedersoo L, 2013. Ectomycorrhizal fungal communities associated to Nothofagus species in Northern Patagonia. Mycorrhiza 23, 487-496.

Ortiz-Jaureguizar E, Cladera GA, 2006. Paleoenvironmental evolution of southern South America during the Cenozoic. Journal of Arid Environments 66, 498-532. 
Peintner U, Bougher NL, Castellano MA, Moncalvo JM, Moser MM, Trappe JM, Vilgalys R, 2001. Multiple origins of sequestrate fungi related to Cortinarius (Cortinariaceae). American Journal of Botany 88, 2168-2179.

Peterson KR, Pfister DH, Bell CD, 2010. Cophylogeny and biogeography of the fungal parasite Cyttaria and its host Nothofagus, southern beech. Mycologia 102, 14171425.

Rambaut A, Drummond AJ, 2007. Tracer v1.5.

Raven PH, Axelrod DI, 1972. Plate tectonics and Australasian paleobiogeography.

Science 176.

Redhead SA, Vizzini A, Drehmel DC, Contu M, 2016. Saproamanita, a new name for both Lepidella E.-J. Gilbert and Aspidella E.-J. Gilbert (Amaniteae, Amanitaceae). IMA FUNGUS 7, 119-129.

Ronquist F, Teslenko M, van der Mark P, Ayres DL, Darling A, Hohna S, Larget B, Liu L, Suchard MA, Huelsenbeck JP, 2012. MrBayes 3.2: efficient Bayesian phylogenetic inference and model choice across a large model space. Systematic Biology 61, 539542.

Ryberg M, Matheny PB, 2012. Asynchronous origins of ectomycorrhizal clades of Agaricales. Proc Biol Sci 279, 2003-2011.

Sánchez-Ramírez S, Etienne RS, Moncalvo J-M, 2015a. High speciation rate at temperate latitudes explains unusual diversity gradients in a clade of ectomycorrhizal fungi. Evolution 69, 2196-2209.

Sánchez-Ramírez S, Ryberg M, Wilson AW, 2017. An overview of phylogenetic and historical approaches to mycorrhizal biogeography, diversity, and evolution, in: 
Tedersoo L (ed), Biogeography of mycorrhizal symbiosis. Springer International Publishing, p. in press.

Sánchez-Ramírez S, Tulloss RE, Amalfi M, Moncalvo J-M, 2015b. Palaeotropical origins, boreotropical distribution, and increasing rates of diversification in a clade of edible ectomycorrhizal fungi (Amanita sect. Caesareae). Journal of Biogeography 42, 351-363.

Sanmartin I, Ronquist F, 2004. Southern hemisphere biogeography inferred by event-based models: plant versus animal patterns. Systematic Biology 53, 216-243. Schickmann S, Urban A, Krautler K, Nopp-Mayr U, Hacklander K, 2012. The interrelationship of mycophagous small mammals and ectomycorrhizal fungi in primeval, disturbed and managed Central European mountainous forests. Oecologia 170, 395-409.

Sheedy EM, Ryberg M, Lebel T, May TW, Bougher NL, Matheny PB, 2016. Dating the emergence of truffle-like fungi in Australia, by using an augmented meta-analysis. Australian Systematic Botany 29, 284-302.

Singer R, 1954. Agaricales von Nahuel Huapi. Sydowia 8, 100-157.

Skrede I, Engh IB, Binder M, Carlsen T, Kauserud H, Bendiksby M, 2011. Evolutionary history of Serpulaceae (Basidiomycota): molecular phylogeny, historical biogeography and evidence for a single transition of nutritional mode. BMC Evolutionary Biology 11, 230-230.

Stamatakis A, 2014. RAxML version 8: a tool for phylogenetic analysis and postanalysis of large phylogenies. Bioinformatics 30, 1312-1313. 
Tedersoo L, Bahram M, Polme S, Koljalg U, Yorou NS, Wijesundera R, Villarreal Ruiz L, Vasco-Palacios AM, Thu PQ, Suija A, Smith ME, Sharp C, Saluveer E, Saitta A, Rosas M, Riit T, Ratkowsky D, Pritsch K, Poldmaa K, Piepenbring M, Phosri C, Peterson M, Parts K, Partel K, Otsing E, Nouhra E, Njouonkou AL, Nilsson RH, Morgado LN, Mayor J, May TW, Majuakim L, Lodge DJ, Lee SS, Larsson KH, Kohout P, Hosaka K, Hiiesalu I, Henkel TW, Harend H, Guo LD, Greslebin A, Grelet G, Geml J, Gates G, Dunstan W, Dunk C, Drenkhan R, Dearnaley J, De Kesel A, Dang T, Chen X, Buegger F, Brearley FQ, Bonito G, Anslan S, Abell S, Abarenkov K, 2014. Fungal biogeography. Global diversity and geography of soil fungi. Science 346, 1256688.

Tedersoo L, Bahram M, Toots M, Diedhiou AG, Henkel TW, Kjoller R, Morris MH, Nara K, Nouhra E, Peay KG, Polme S, Ryberg M, Smith ME, Koljalg U, 2012. Towards global patterns in the diversity and community structure of ectomycorrhizal fungi. Molecular Ecology 21, 4160-4170.

Tedersoo L, Jairus T, Horton BM, Abarenkov K, Suvi T, Saar I, Koljalg U, 2008. Strong host preference of ectomycorrhizal fungi in a Tasmanian wet sclerophyll forest as revealed by DNA barcoding and taxon-specific primers. New Phytologist 180, 479490.

Tedersoo L, May TW, Smith ME, 2010. Ectomycorrhizal lifestyle in fungi: global diversity, distribution, and evolution of phylogenetic lineages. Mycorrhiza 20, 217263.

Tedersoo L, Smith ME, 2013. Lineages of ectomycorrhizal fungi revisited: Foraging strategies and novel lineages revealed by sequences from belowground. Fungal Biology Reviews 27, 83-99. 
Thiers HD, 1984. The secotioid syndrome. Mycologia 76, 1-8.

Trappe JM, Molina R, Luoma DL, Cázares E, Pilz D, Smith JE, Castellano MA, Miller SL, Trappe MJ, 2009. Diversity, ecology, and conservation of truffle fungi in forests of the Pacific Northwest. Gen. Tech. Rep. PNW-GTR-772; U.S. Department of Agriculture, Forest Service, Pacific Northwest Research Station, Portland, OR, pp. 1194.

Truong C, Mujic AB, Healy R, Kuhar F, Furci G, Torres D, Niskanen T, Sandoval-Leiva PA, Fernández N, Escobar JM, Moretto A, Palfner G, Pfister D, Nouhra E, Swenie R, Sánchez-García M, Matheny PB, Smith ME, 2017. How to know the fungi: combining field inventories and DNA-barcoding to document fungal diversity. New Phytologist, online early.

Tulloss RE, 2005. Amanita-distribution in the Americas with comparison to eastern and southern Asia and notes on spore character variation with latitude and ecology. Mycotaxon 93, 189-231.

Tulloss RE, Halling RE, 1997. Type studies of Amanita morenoi and Amanita pseudospreta and a reinterpretation of crassospores in Amanita. Mycologia 89, 278288.

Tulloss RE, Kuyper TW, Vellinga EC, Yang ZL, Halling RE, Geml J, Sánchez-Ramírez S, Gonçalves SC, Hess J, Pringle A, 2016. The genus Amanita should not be split. Amanitaceae 1, 1-16.

Wilson AW, Hosaka K, Mueller GM, 2017. Evolution of ectomycorrhizas as a driver of diversification and biogeographic patterns in the model mycorrhizal mushroom genus Laccaria. New Phytologist 213, 1862-1873. 
Wolfe BE, Kuo M, Pringle A, 2012a. Amanita thiersii is a saprotrophic fungus expanding its range in the United States. Mycologia 104, 22-33.

Wolfe BE, Tulloss RE, Pringle A, 2012b. The irreversible loss of a decomposition pathway marks the single origin of an ectomycorrhizal symbiosis. PLoS One $\mathbf{7}$, e39597.

Figure 1. Bayesian Inference (BI) majority rule consensus tree from a concatenated dataset of nuclear 18S and 28S ribosomal DNA as well as mitochondrial $16 \mathrm{~S}$ and $26 \mathrm{~S}$ DNA. Posterior probabilities (PP) and bootstrap support (BS) from the maximum likelihood (ML) tree are indicated with thick branches (black for $\mathrm{PP} \geq 0.95$ and $\mathrm{BS} \geq 70$, grey for $\mathrm{PP} \geq 0.90$ and $\mathrm{BS} \geq 60$, black dashed line for $\mathrm{PP} \geq 0.95$ only, grey dashed line for BS $\geq 70$ only). Sequestrate Amanita species are in bold. South American species are highlighted in blue and Australian species in green. The genus Amanita is subdivided into two highly supported clades corresponding to subgenera Amanita and Lepidella, while non-ectomycorrhizal species form paraphyletic sister lineages. The new species $A$. nouhrae clusters with other sequestrate species from Australia in a highly supported southern temperate clade (highlighted in grey) that is composed of both sequestrate and epigeous agaricoid taxa.

Figure 2. Time-calibrated maximum-clade-credibility tree of the genus Amanita. Only nodes with posterior probability $\geq 0.9$ are annotated with horizontal bars representing 95\% highest posterior densities (HPD). Individual species are color-coded by the region 
where they were found: North America (orange), Eurasia (purple), Africa (red), northern South America (yellow), southern South America (blue), and Australia (green). Names are only shown for Australian and southern South American taxa. Nodes that represent divergence events resulting in an Australian or southern South American lineage are highlighted with a black rhombus. Geological epochs are marked at the bottom. Those abbreviated represent the Paleogene $(\mathrm{Pg})$, the Oligocene $(\mathrm{O})$, the Pliocene $(\mathrm{Pl})$, and the Pleistocene (P), respectively.

Figure 3. Amanita morenoi. A. Striated pileus with scaly patches of universal veil; white lamellae with approximately one lamellula in between each lamella (MES1774, Bar $=1$ $\mathrm{cm})$. B. Lightly fibrillose stipe, whitish towards the apex, with concolorous striated annulus; bulbous base encircled by circumsessile volva (MES1774, Bar $1 \mathrm{~cm}$ ). C. Smooth and white context trama, becoming hollow towards the base of the stipe, slightly darker pileipellis evident in cross section (MES1301, Bar $2 \mathrm{~cm}$ ). D. Globose basidiospores ornamented on the inner wall with small, evenly distributed, hemispherical pits (MES1624, Bar $5 \mu \mathrm{m}$ ). E. Hymenium showing clavate basidia with short sterigmata and dense subhymenium consisting of tightly interwoven hyphae (MES1624, Bar $10 \mu \mathrm{m}$ ).

Figure 4. Macroscopic characteristics of Amanita nouhrae. A. Holotype collection (MES1921, Bar $1 \mathrm{~cm}$ ). B. Mature basidiomes showing the thin peridium, loculate gleba, and reduced, conical to subglobose sterile base (MES1921, Bar $5 \mathrm{~mm}$ ). C. Immature basidiome with whitish peridium and gleba; sterile base distinctive and subglobose 
(MES1213, Bar $5 \mathrm{~mm}$ ). D. Close-up photograph showing the gleba with irregular, angular to circular locules; peridium thin and almost undistinguishable, with universal veil remnants forming patches on upper surface (MES1921, Bar 0.5 mm).

Figure 5. Microscopic characteristics of Amanita nouhrae. A. Locule in section showing the hymenial and subhymenial trama (MES1921, Bar $50 \mu$ m). B. Hymenium with abundant basidiospores, accumulating from basidia collapsing at maturity; subhymenium dense, consisting of tightly interwoven hyphae (MES1921, Bar $20 \mu \mathrm{m}$ ). C. Single-spored basidia that support thick-walled and distinctly ornamented basidiospores. D. Immature basidium with three young basidiospores (MES1213, Bar=10 $\mu$ m). E. Hymenial hypha with septum and clamp connection (MES1213, Bar $20 \mu \mathrm{m}$ ). F. Thick-walled and distinctly ornamented mature basidiospores; ornamentation consisting of irregular cavities offering a false verrucose appearance obscured by the pronounced oil droplet (MES1921, Bar $5 \mu \mathrm{m}$ ). G. Immature basidiospores with a thin, smooth wall and distinct oil droplet (MES1213, Bar $5 \mu \mathrm{m}$ ). H. Peridium composed of large, irregularly packed polyhedral cells (MES1921, Bar $20 \mu \mathrm{m})$. 

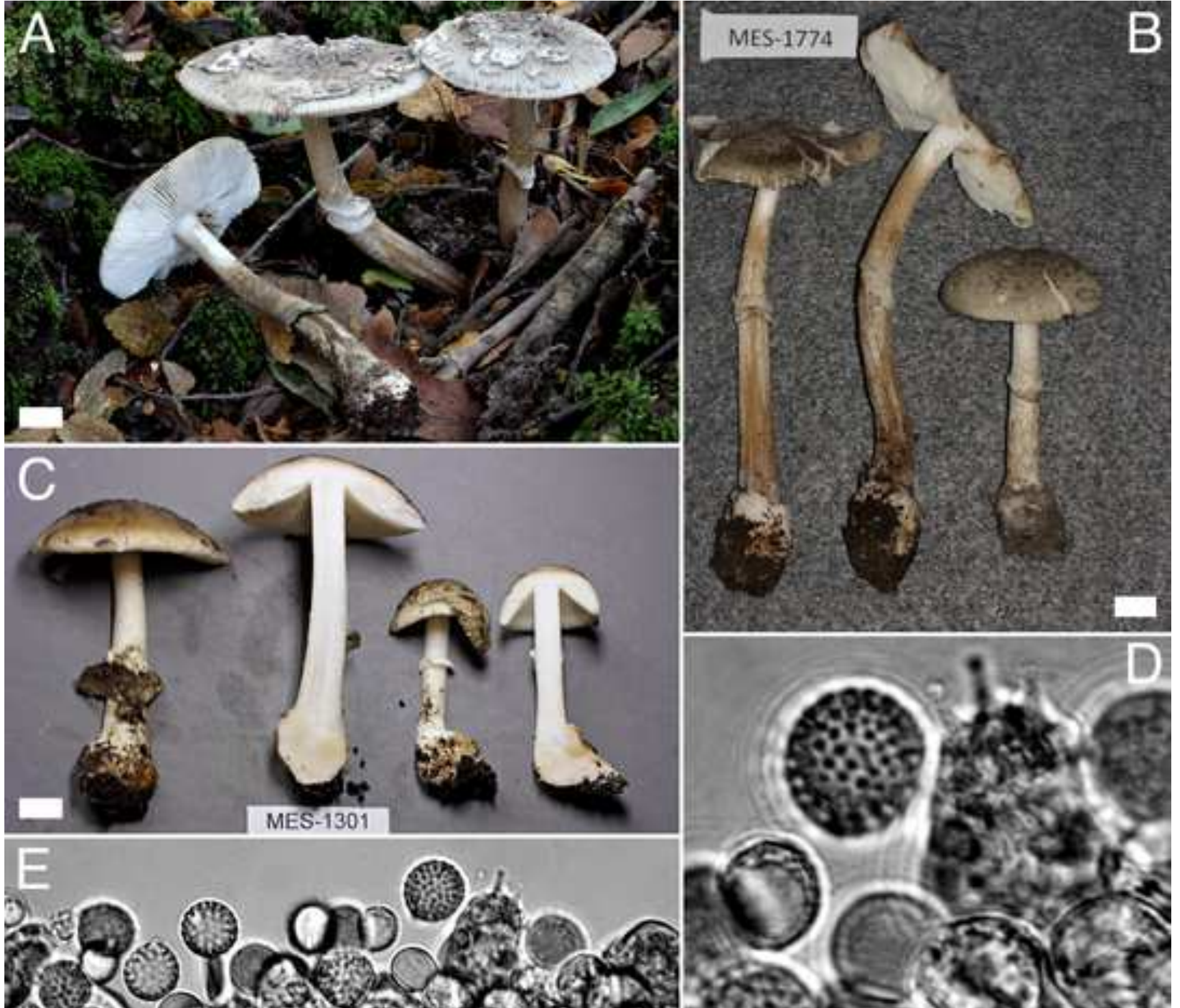

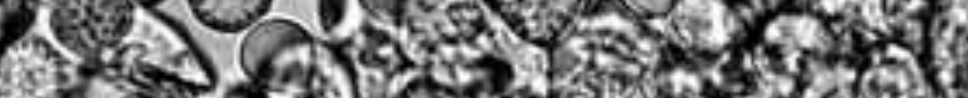

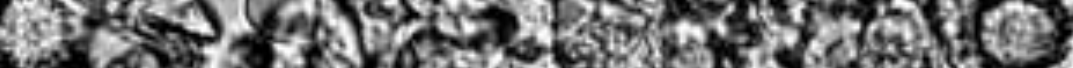

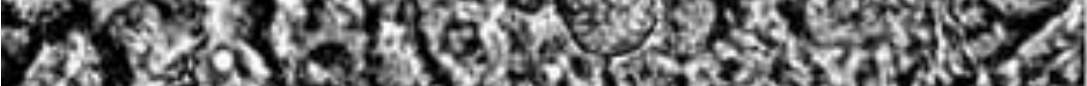

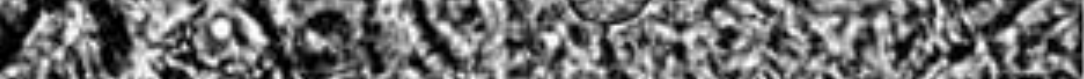

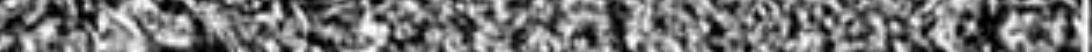

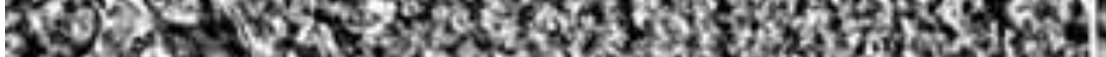
(4)

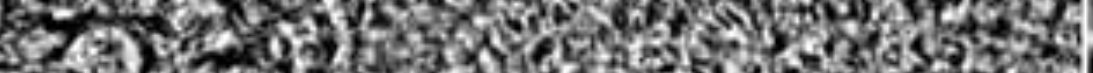

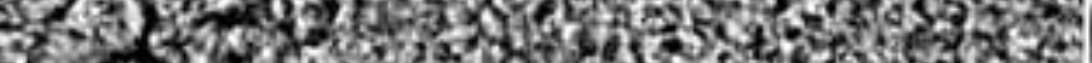

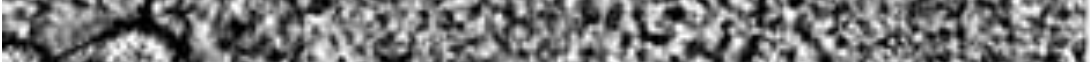

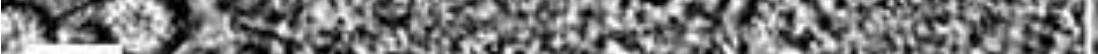

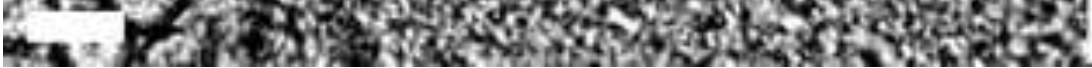

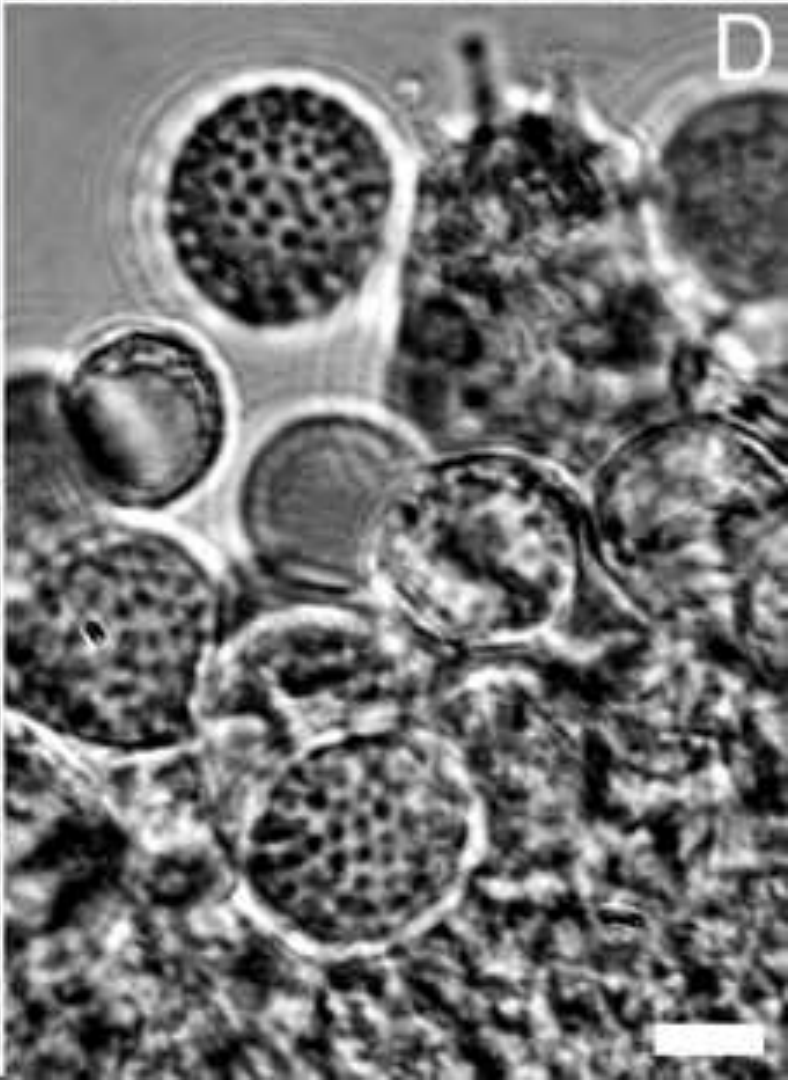




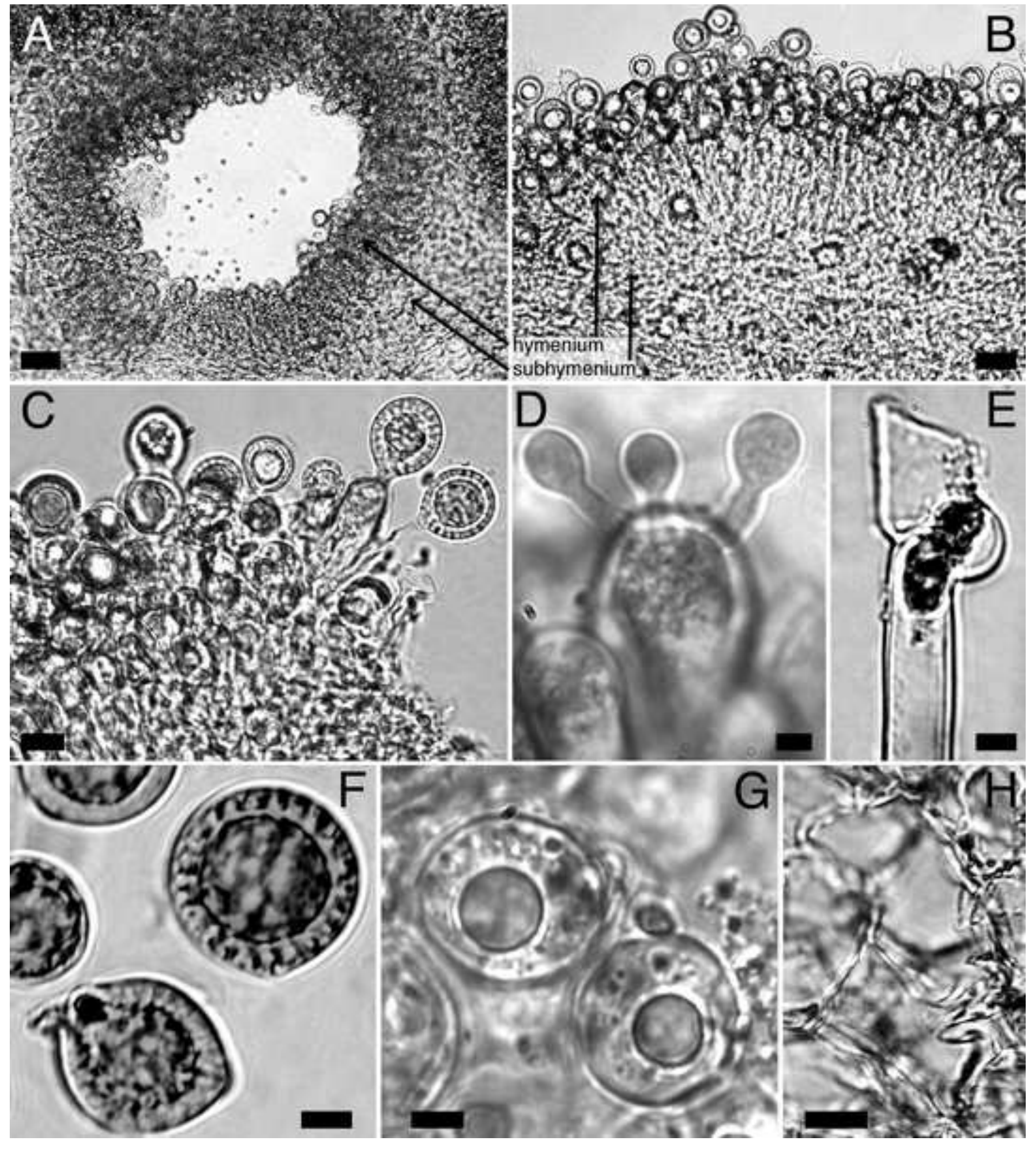

